\title{
Reducing academic isolation in favour of learning relationships through a virtual classroom
}

\section{Dr Michael Goldrick}

National College of Ireland, Ireland

Dr James O'Higgins Norman

Dublin City University, Ireland

\begin{abstract}
Due to geographical distances and sporadic contact with peers and faculty members, many off-campus or distance learners experience feelings of inadequacy, reduced selfconfidence and other social anxieties. As a means to reduce and avoid these consequences of academic isolation, Higher Education Institutes have traditionally used asynchronous forms of communication in order to bridge these geographical gaps. However, due to advances in technology it is now possible to offer distance learners the opportunity to communicate synchronously with their peers and their teachers, as they would in a real classroom. In accordance with these developments, this research examines the development of a virtual learning support service in National College of Ireland. Using survey results, online student feedback and semester results, this research will present how the problem of academic isolation was reduced in National College of Ireland by incorporating the use of a virtual classroom. Presenting screen shots and a review of online teaching, the research will illustrate how a learning support service can become more flexible and student centred.
\end{abstract}

Keywords: academic isolation; virtual classrooms; student-centred; learning support. 


\section{Introduction}

Although much of 'The Idea of A University' put forward by Newman in the $19^{\text {th }}$ century has been set aside and even deemed irrelevant to the context of higher education today (Roberts, 1990; Reddings, 1996), others have argued for a renewed and more balanced analysis of Newman's ideas as an antidote to a sometimes overly mechanistic view of higher education today (MacIntyre, 2009). Newman (1909, p.74) himself warned that an:

Academical system without the personal influence of teachers upon pupils, is an arctic system; it will create an ice-bound, petrified, cast-iron University, and nothing else.

Core to Newman's idea was his assumption that higher education should be experienced as a community in which students were supported to learn a number of disciplines in an integrated fashion. For Newman, education was not merely about learning but also about a concern and care for the person. If we allow a modicum of acceptance of these ideas today we are faced with a significant challenge, particularly when we consider the thousands of students who are increasingly registering on part time or distance programmes of study. While the idea of the university as a warm and caring environment in which students thrive may be somewhat achievable when both lecturers and students are on campus together, it is far more likely that distance and part-time students will experience social and academic isolation due to the nature of their programmes of study.

Social and academic isolation has been shown to be detrimental for the learning process, ultimately hindering the socialisation process within education (Ryan and Glenn, 2004), or what Lee and Chan (2007) call the acculturation into institutional life. This lost opportunity can often lead off-campus students or distance learners to use their time ineffectively and can ultimately induce feelings of inadequacy, reduced self-confidence and other social anxieties (Rowntree, 1992; Smyth, 2005; Wood, 1995). The problem of social and academic isolation can be considerably accentuated when learners are located off campus and are engaged in distance and blended learning.

As a means to reduce and avoid the consequences of isolation for distance learners, Higher Education Institutions have continually aimed to bridge geographical gaps using technology (Harper et al., 2000; Collis and Moonen, 2001). Arising from our concern to 
increase connectivity, this paper reports on how we used an action research approach in order to overcome the problem of social and academic isolation (Becker and Watts, 2006) in National College of Ireland. Utilising screen-shots and a review of recorded sessions, we will demonstrate how a virtual classroom (Wiziq, 2010) was utilised to offer individual support and workshop support to first year undergraduate distance learners. To begin, we will present the theoretical approach taken to the research and the context in which the research took place. Following this, a review of current synchronous and asynchronous strategies to reduce academic isolation will be offered. From here, we will present our own search for a virtual class that matched our program objectives (Myers et al., 2004). Presenting then the initial trial of a virtual learning support service, we will describe how qualitative and quantitative methods were used to evaluate the initiative and will provide some insight into our findings and experiences.

\section{Theoretical framework}

In so far as our intention was to address an identified problem, academic isolation for distance learners within a specific educational context, it was clear to us that our research could be classified as an action research project (Carl and Kemmis, 1986; Stenhouse, 1975; Lewin, 1946).

\section{Context}

The research was carried out in National College of Ireland from late 2008 to 2010, when feedback about the Learning Support Service highlighted that distance learning students felt isolated from their peers, faculty and support staff. Feedback was gathered by way of an online survey to which 44 out of 112 students responded. Students had been specifically asked to comment on their experience of learning support. Results from the survey indicated that $87 \%$ of students were satisfied with both the content and delivery of support workshops. However, additional comments from respondents raised particular issues in relation to geographic isolation and infrequency of contact with staff at the main campus: 
Maybe specific workshops course related? Part time courses (day released in my case) can feel quite fast paced and extra support would be appreciated. (NCI Student, 2009)

Not at this time, but one to one support next term does seem appealing. ( $\mathrm{NCl}$ Student, 2009)

We are out in Tallaght and at times feel at bit out of the college but I don't have any suggestions as how this could be overcome. (NCI Student, 2009)

From these comments, the Learning Support Service identified an established theme of academic isolation (Becker and Watts, 2006) and a need to adapt our existing on-campus service to be more supportive and flexible in order to meet the needs of distance learners. Having then a purpose to utilise technology in order to meet the wider needs of students, we began exploring possible avenues for virtual support.

\section{Reviewing current strategies to reduce academic isolation}

Taking a collaborative and student-centred approach (Brooks, 2003; Hardy et al., 2009) to this exploration, we felt it necessary to firstly review the types of online supports that were available to students and to consider how these services could be expanded. To do this, it was important to consider the types of supports that institutes can presently utilise, namely asynchronous and synchronous communication.

\section{Asynchronous communication}

As an established form of education, distance learning can be traced back to the late $18^{\text {th }}$ century, when Caleb Phillips began offering home study courses on how to learn shorthand through the Boston Gazette (Holmberg, 2005). This asynchronous delivery of materials would become the basis for subsequent distance learning courses and was first embraced by the University of London (2009), who began offering distance learning degrees as early as 1858 . These mail-based mechanisms are still an intricate part of many distance learning programmes today, allowing learners to receive hard copies of text and other materials mirroring those provided to on-campus students. 
Building on this initial structure, the role of technology has further increased the levels of asynchronous communication that can occur between students and colleges. Most notable of these advancements has been the use of e-mail, moodle, audio cassettes, videos and most recently web-based courses, which allow multiple users to work at their own pace and contribute to online forums and discussions at staggered intervals (Fusco and Ketcham, 2002). In National College of Ireland, asynchronous learning support was delivered through e-mail communication, the postage of support materials and downloadable presentations through the student intranet. Through these communicative tools, one can argue that distance learners were receiving a considerable amount of learning support which equated, in quantity at least, to that of their on-campus full time counterparts.

Shearer (2003) claims that distance and off-campus learning is just as complex as face-toface interaction and suggests that educators should be concerned with how best to engage students studying through distance learning. Essentially, Shearer (2003) considered whether educators can really relate to students through asynchronous communication alone. Barnes (1995) does not think so, highlighting that asynchronous tools do not capture non-verbal communications, the posture, sense of attention and perhaps most importantly the 'light bulb' effect, which identifies the grasp of an idea. Similarly, Power (1990) concludes that it is through the spoken word and synchronous discourse that content is personalised, through subtle nuances and emphasis. From a constructivist perspective, this synchronous communication (Fusco and Ketcham, 2002) is perhaps the most valuable tool an educator can possess and one which is even more important when trying to scaffold a person's understanding of their learning potential or learning difference.

\section{Synchronous communication}

Bearing in mind the critiques of Barnes (1995) and Power (1990), it is possible to create three prerequisites for effective synchronous communication for distance learners:

1. Students can see each other and the tutor in real time.

2. Students can hear, or read instructions from the tutor in real time.

3. The relational dynamics of interpersonal synchronous learning can be used to motivate students. 
These prerequisites are not, however, easily accomplished with distance learners in a virtual learning environment and as such the conceptual boundaries of educational technology are continuously being expanded. It is not surprising that many of the educational technologies available today were first imagined by science fiction writers such as Forster (1909). Predating the invention of asynchronous e-mail (what he calls pneumatic post) and synchronous videoconferencing, Forster (1909) introduced the immediate benefits and potential danger of over relying on technology, such as the replacing of clinical judgement with computer-based systems (Campbell et al., 2007).

Other forms of synchronous communication that are available in higher education include instant messaging systems and videoconferencing (Fusco and Ketcham, 2002), which has evolved as a result of computer systems (Bitzer et al., 1965), teletext/videotext (Muter, et al., 1980) and the internet (Abbate, 2000). Yet whilst phone, facsimile and internet usage became popular across all sectors of education in the twentieth century, the cost and quality of early videoconferencing packages seemed to hinder their incorporation into distance education (Smyth, 2005). In more recent years, these initial difficulties have seemed to be adequately dealt with through broadband technology which, being faster and cheaper, has allowed universities and schools to more fully explore the benefits of using videoconferencing as a means to decrease isolation and create the relational dynamics (Bates, 1997) similar to those experienced by teachers and students on campus. Much like Forster's (1909) vision, the videoconferencing system has been most commonly used to connect main campus centres with more remote centres, as well as to facilitate virtual or electronic field trips (Newman et al., 2008). Despite, however, the benefits of such systems, the cost of installation and maintaining the needed hardware and software as well as a degree of unreliability with broadband led us to continue our search for a more economically viable way to create a virtual support service. To aid the development of our initiative we adopted a methodology similar to Myers et al.'s (2004, p.124) in order to identify six program objectives that would help guide our eventual decision:

1. The program should not require complicated downloads or operations.

2. Students could have the option of seeing the tutor.

3. Students could talk to the tutor.

4. Students could message the tutor.

5. Materials could be presented and corrected online.

6. Online classes could be recorded and used for revision. 
Using these criteria, several programmes for virtual classrooms were identified - Wiziq (www.wiziq.com); DimDim (http://www.dimdim.com/); and Elluminate (http://www.elluminate.com/). Not to be confused with a Learning Management System, or a virtual learning environment such as Moodle (http://moodle.com/) or Blackboard (http://www.blackboard.com), a virtual classroom is used to facilitate live interaction between peers and/or tutors, who can collaborate as they would in a live classroom (Fusco and Ketcham, 2002; Roxanne Hiltz, 2006). This specific interaction is achieved through text, speech and visual communication which can, depending on the provider, be recorded for wider distribution or revision. As a way to help us choose between Wiziq, DimDim and Elluminate, we firstly compared each classroom using the following screening criteria:

1. Is there a download necessary?

2. Is there a virtual whiteboard?

3. Can sessions be recorded?

4. Is the tool free to use?

Based on these four key areas, we believed that Wiziq was the strongest of the three models as it did not require a download, it had a virtual whiteboard, sessions could be recorded and it was free to use.

Table 1. Comparison of virtual classrooms.

\begin{tabular}{|l|l|l|l|l|}
\hline Classroom & Download necessary & Virtual whiteboard & Recording of sessions & Free \\
\hline Wiziq & No & Yes & Yes & Yes \\
\hline DIMDIM & Yes & Yes & No & Yes \\
\hline Elluminate & Yes & Yes & Yes & No \\
\hline
\end{tabular}

To supplement our initial findings, we later participated in an online Moodle discussion which debated the strengths of the three virtual classrooms (Gates, 2008). In light of our insights gleaned from these discussions, we chose to test the virtual classroom Wiziq, as it had received the most positive replies with regard to Moodle integration, its low cost and ease of use. Building on this Moodle evaluation, we sought the help of a critical friend in University College Dublin who helped to Acceptance test (Myers et al., 2004) the 
classroom in terms of accessibility and quality. As part of this testing, the following areas were discussed:

Question 1: Is the layout easy to understand?

Question 2: How is the sound and picture? Are you experiencing any delays?

Question 3: Would you find it helpful to have virtual lectures?

Question 4: Are there any features that you think are missing or that you would like?

From this process, we established that Wiziq was easy to use and could be a real alternative to a live teaching environment. However, beyond the technology element, this initial discussion also allowed us to consider whether there were any pedagogic differences between an online and live teacher or tutor.

\section{The online tutor}

Agreeing with McMann (1994), Gerrard (2002; 2005) claims that face-to-face teaching and online teaching have many similar traits. Gerrard (2002; 2005) does however make the point that there remains a significant set of differences which should not be ignored or avoided. In particular, Gerrard (2002; 2005) and McPherson and Nunes (2004) argue that online learning generates multiple discourses and multiple starting points for individual students and argue that an online tutor must be prepared to work collaboratively with students, scaffolding their knowledge appropriately and non-linearly. This is perhaps the most interesting facet of online teaching, where teacher-centred pedagogy is not only unfashionable but is plainly ineffective as students need to be stimulated and guided using appropriate learning strategies. To help with this development of student-centred teaching, we looked to the works of Gagne (1985) and Illeris (2001; 2003; 2006). Using Gagne's first event of instruction, we began to think about how we could induce interest in each learning support workshop, through introducing humour, a provocative opening statement, or asking an intriguing question. From here, it could be then possible to induce a self-directed or collaborative form of problem solving (problem-based learning) (De Graaff and Kolmos, 2007), where the online tutor could facilitate a journey of active learning. Through this experimental process, we believed that we in some small way had begun to create what Illeris $(2001 ; 2003)$ described as a unified concept of learning and teaching. 


\section{Piloting the Virtual Learning Support Service}

As a first step in this pilot, two first-year undergraduate courses, (Higher Cert A and Higher

Cert B) were identified as needing additional learning support in the areas of exam preparation and assignment writing. The decision to use on-campus groups for the initial pilot was taken as a precautionary measure, as any technical or user-related difficulties could be followed up by a live alternate class.

Meeting the groups separately with their lecturer, thirty eight students were introduced to the idea of virtual support (group workshops and individual sessions) and provided with a sign-up sheet if they wished to participate. From these sign-up sheets, twenty four students identified as wanting to take part in the pilot and were given instructions on how to set up an online account needed to participate. In order to control participation in the pilot a decision was made to exclude Wiziq from the wider Moodle environment thus ensuring that only those students who were part of the pilot could participate. This precautionary isolation offered the benefits of a later dissemination and further championing if the pilot proved to be successful or, if unsuccessful, would avoid technology contamination within both faculty and students. In terms of providing equitable supports to all students on the Higher Cert A and Higher Cert B courses, supplementary live sessions were made available for those students who did not wish to participate in the online sessions. Having earlier tested the program successfully from a technical and navigation perspective, the Virtual Learning Support Service was piloted in mid-December 2009, when we began offering virtual workshops and virtual individual support sessions using Wiziq.

\section{Virtual workshops for Organisational Behaviour and Business Communications}

Learning support workshops allow tutors to present learning strategies and technologies to small or large groups of students in National College of Ireland. These workshops generally relate to core academic skills such as learning styles, study skills, presentation skills, academic writing, and exam revision. In this particular case, the tutor was attempting to reinforce exam skills by catering workshops around a specific theme or subject. This was achieved using slides provided to the support tutor by the course lecturer (Hurley, 2009a; Hurley, 2009b). 
These sessions catered for twenty-two full-time students who signed up for group support (three traditional sessions, mirrored by three virtual). For continuous assessments, two workshops were created that married lecture material and sample questions from the lecturer. Both of these workshops incorporated an in-class mock examination using a simplified voting system of hand raising or letter calling to signal their choice of answer. This method sought to infuse a 'gaming culture' within the tutorial, a method becoming increasingly popular as a format to increase attention and aid recall (Dror, 2008).

\section{Figure 1. Screenshot of online exam.}

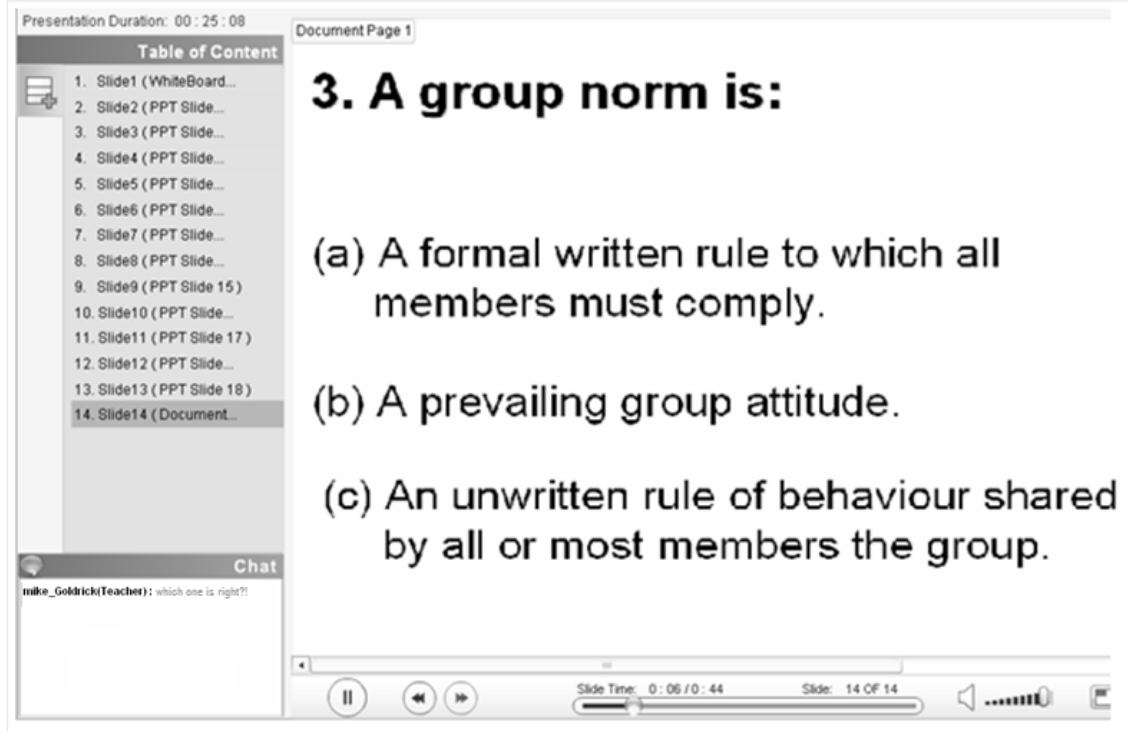

Using this method, a question with three possible answers was firstly posed to the group. Following this, each attendant in both live and virtual sessions were then asked to raise their hand, call out, or type A, B, C (in a virtual setting), for whichever option they felt was the correct answer. Correct answers were then presented and followed by a virtual applause using PowerPoint sounds, which in many cases added an element of fun and a 'game show' type construction to the support session.

The final two workshops (one live and one virtual) focused on how to plan and write out exam answers effectively, offering example introductions, paragraph building advice and time-keeping techniques. For any student who could not attend either live or virtual sessions, a pre-recorded version of the class was sent to their e-mail accounts. These recordings were also e-mailed to part-time students who could not attend live or virtual support lectures due to work commitments. It is important to note, however, that the 
recording facility motivated many full-time and part-time students to directly request a link to a pre-recorded version of tutorials, which were then used in connection with traditional sessions. This is perhaps evidence that virtual classrooms are not only useful for reducing academic isolation but can be used to increase student convenience (Picciano, 2006).

\section{Quantitative effect of support tutorials}

In order to examine the effect of the Learning Support Service's blended intervention, we firstly used the group's semester one results as a baseline of performance (Wiezel, 1998; Kaufman et al., 2000; Zywno, 2002). Bearing in mind that the pre-intervention group average was $42 \%$, the post-intervention scores of $56 \%$ indicate an overall improvement in semester two of $14 \%$, within both the Continuous Assessments and exam results. This improvement is gathered from the scores of the twenty-two students who utilised three exam revision workshops in semester two (either live, virtual or both versions). In order to critically assess whether this improvement was due to the impact of the service or merely through chance, we chose to use a Chi-square, non-parametric test (Greenwood and Nikulin, 1996), to examine pre-intervention pass rates and post intervention pass rates. The result of this particular Chi-square test (Lambert, 2009) as seen below (11.45833333, where the rate of probability was calculated at $10 \%$ ) offers a statistically successful acceptance of the idea that learning support workshops can positively affect exam performance.

\section{Figure 2. Chi square.}

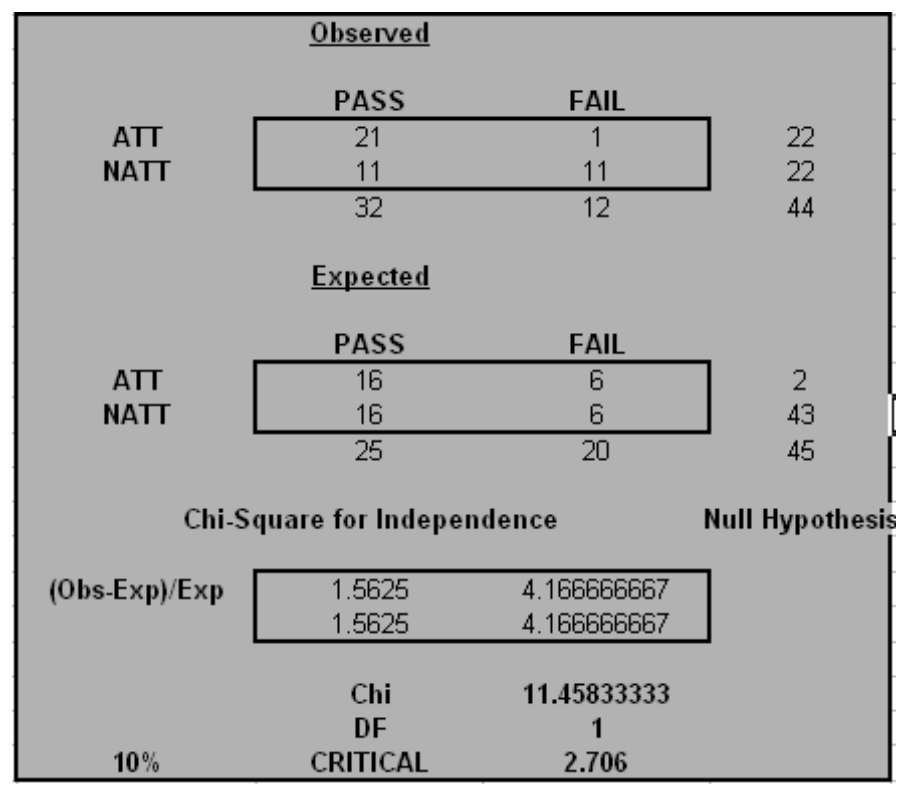


Furthermore, whilst it cannot be claimed that such a significant result was solely due to the virtual/live intervention, it can be argued that the consistency of improved scores indicates that those students who attended both the live and/or virtual sessions received the same quality of support. What has perhaps been a testament to this theory, are the consistent requests from students who have asked for a link to a virtual session when work or illness prevented their attendance.

\section{Virtual individual support for Business Communications}

Individual support sessions allow tutors to reinforce support materials and strategies with a single student, giving them the opportunity to ask questions and develop their own understandings. This was an important next step in the research cycle as it allowed us to explore whether Wiziq would be a suitable tool to replicate live individual support sessions.

In this particular case (semester two of 2009), we attempted to reinforce elements of critical thinking and exam revision with a student who was studying for a Business Communications exam (the student had previously signed a declaration of consent regarding the Wiziq trial). Having missed the relevant lecture (Assertiveness and Influence), the student in question had made an attempt to study from home but had encountered difficulties in understanding the various topics. Encountering then a situation where a face-to-face meeting with the student would not be possible (as he remained absent from college), we offered the student the opportunity to engage with the support service online.

This session was broken up into two sections:

1. A review of the in-class lecture slides.

2. A set of sample exam questions. 


\section{A review of the in-class lecture slides}

The first stage of this process worked very well where, after some initial voice delay, the experience of the virtual environment proved to be both novel and plainly advantageous for the student who could not come to campus. Adapting well to the interaction process, the student felt comfortable in asking questions throughout the presentation phase and was receptive to both encouragement and self-evaluation.

\section{Figure 3. Screenshot of virtual class.}

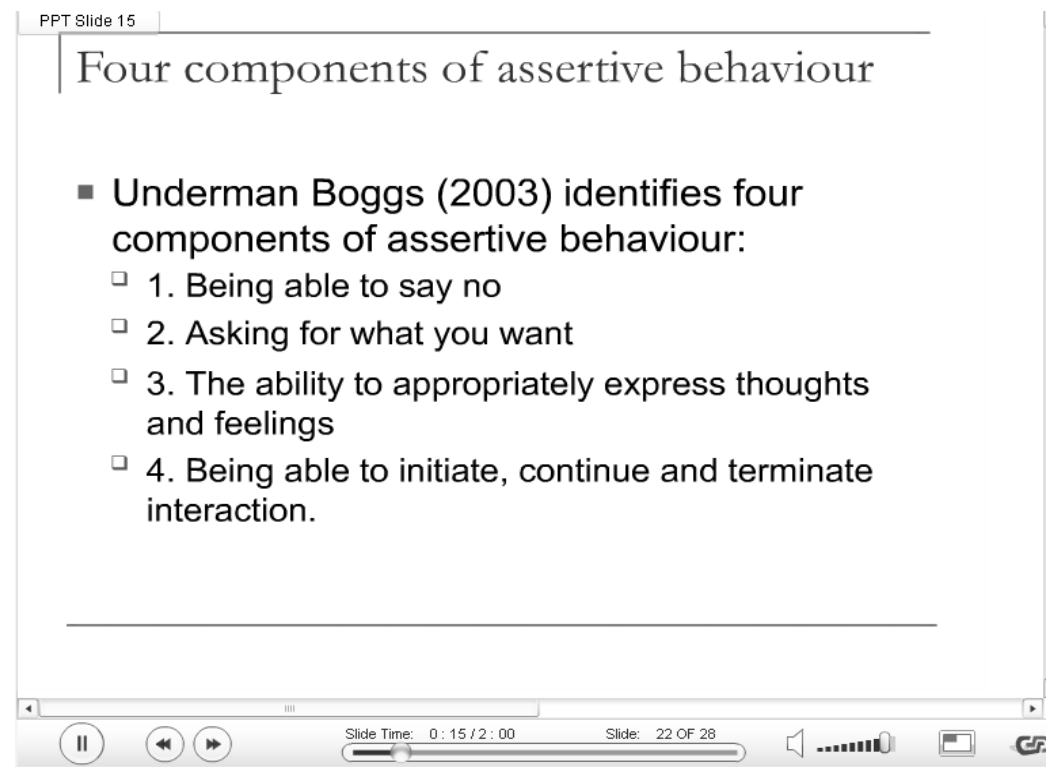

As can be seen above in figure 3 , the content of the lecture slides focused around a number of contemporary communication theories that the students were expected to both know and understand. With this task in mind, the student agreed to explore the differences between aggressive and assertive behaviour, in a mock exam scenario which would determine his own understanding of the presented material. After going through the PowerPoint presentation, the student and tutor began to formulate example exam questions based on the information at hand. As the test itself was scheduled as a CA (Continuous Assessment) class test (worth 25\%), the potential questions asked would require concise answers. One example of these questions was:

Mike: What are the four components of assertiveness? 
In attempting to answer this question, the student had some trouble in organising the material into his own words effectively, which in turn required the student and tutor to talk about assertiveness as a concept:

Mike: Alright Liam (Pseudo name), let's think about this for a moment. What does it mean to be assertive? [Pause] I think being assertive means being honest with a person about what you want, without being aggressive or ignoring another person's own desire.

Through this dyadic, the student began to internally process the concept of assertive behaviour in a professional context and ultimately began to form his own understanding of the material. In order to test this understanding, the student was then asked to write out his answer to the following question as he would in a real exam situation:

Mike: Give a scenario of an aggressive, passive and assertive response in a person?

In the next screenshot this very process can be seen, where both the student and tutor utilised the communal whiteboard:

\section{Figure 4. Screenshot of online interaction.}

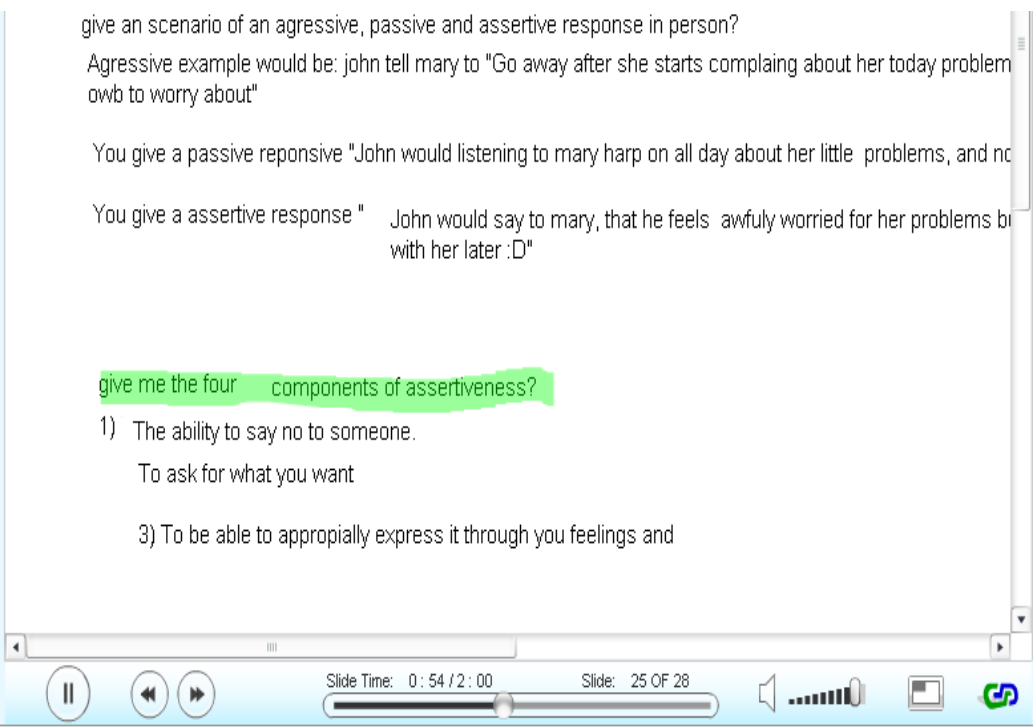


Taking the writing controls, the student then wrote out what he believed to be an aggressive, passive and assertive response:

Student: An aggressive example would be, John tell mary to "Go away after she starts complaining about her today problems".

Passive response: "John would listening to mary harp on all day about her little problems and not say anything".

Assertive response: "John would say to mary, that he feels awfully worried for her problems but can't talk about them now but maybe will talk them over with her later".

As can be seen from figure 4, the whiteboard area is a vital component of the virtual classroom's unique benefit, where the tutor and student can potentially use the same space to both pose questions and construct answers in real time. Continuing with this, the next question the tutor asked the student was in relation to the four components of assertiveness. In this particular example, the student had some difficulty in organising the question into a concise answer and felt that the required statements were hard to recall:

Student: The last one is kind of hard isn't it?

Having explained to him that in a short-question based exam the need for short and accurate sentences was vital for high marks, the tutor instructed the student to practise this style of answering on his own and to get comfortable with composing short answers without the aid of the presentation slides. Shortly after this, the student was thanked for attending the virtual class and a follow-up appointment in college was scheduled.

The feedback from this student about his virtual session was very positive and addressed some operational and accessibility concerns that the program might bear:

Student: Yeah it is helpful, yeah, it's pretty good, I enjoy it.

As an added feedback measure, the Wiziq program allows students to rate their experience from 1-5 and also allows a text box area for qualitative comments. This 
particular student's feedback page can be seen below (for security reasons, we have blanked out the student's name).

Figure 5. Feedback from virtual support.

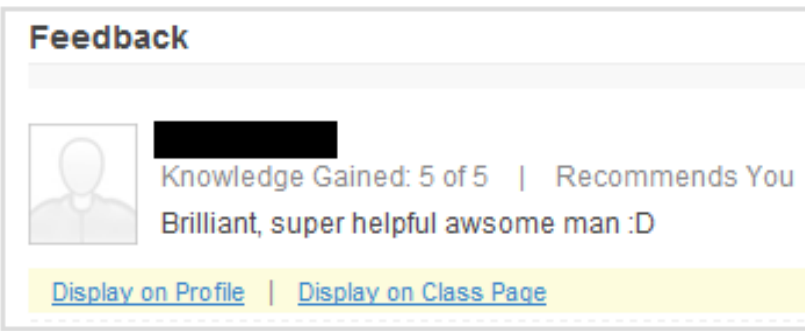

When provided in a constructive manner, this feedback device can help online teachers with the further development of pedagogy, clarity of presentation, pacing, or indeed the tweaking of any materials used in a session (Fry, 2009). Similarly, we feel that this type of feedback would be equally useful for peer review in any teacher training environment or blended learning context.

Beyond these qualitative measures, we felt it important to reflect upon the wider effectiveness of the program itself. To do this, we again adopted a quantitative methodology similar to Wiezel (1998), Kaufman et al. (2000) and Zywno (2002), who suggests that previous results can be used as a benchmark or predictor of future academic performance.

In order to carry out this level of analysis, the students' CA scores for the Communications course were collected (from the lecturer) and compared with the average mark of the Higher Cert A class. This comparison illustrates that the student's individual result of $54.00 \%$ was marginally lower than that of the overall class average of $58.50 \%$. Based on this, it could be argued that the virtual workshop, as the only form of support, provided the student with enough structure and guidance to help him reach a grade that was just short of the average class score. However, we cannot be certain that the student would not have achieved this score without extra support, only that his reaction to the technology was positive.

The student's progress was further evaluated during the end of year exams in Communications, where availing of three traditional and two virtual support sessions, he 
achieved a module grade of $45.5 \%$, which was an increase of $5 \%$ from his semester one result of $40.50 \%$. These individual results however, were lower than the module class average of $56 \%$ which indicates that further support strategies should be explored as a way to help each student to maximise their own potential. Also, when considering the role of virtual support for both on-campus and distance learners, it is crucial to question not only the benefits of increased convenience (Picciano, 2006), but consider the role of introversion and extroversion in the development of learning relationships. Is it possible, as Palloff and Pratt (2007) suggest, that an introverted student will be more attracted to online meetings where social pressures that exist in live scenarios are reduced? If so, we must be careful to create online relations that fully support introverted students, yet simultaneously provide an online experience that does not hinder the development of students who are more comfortable with face-to-face relations.

\section{Establishing the Virtual Learning Support Service}

In light of these initial experiences of virtual learning support, we believed that Wiziq could reduce academic isolation and facilitate the development of meaningful online learning relationships. Based on this belief, the next phase of our research was to more broadly offer virtual support to the whole community in National College of Ireland. This was accomplished in 2010 when we launched the Virtual Learning Support Service, providing all National College Ireland students with the opportunity to engage with their peers and support staff both in a live and online environment.

Since its establishment, the Virtual Learning Support Service has been identified as an example of innovation and good practice at Trinity College Dublin (Doyle, 2010) and has been presented both nationally and internationally. Through this dissemination, we have identified new challenges to online support for distance learners. More specifically, our new research in this area will focus on how to improve the online learning experience for distance learning students with sensory disabilities. 


\section{Conclusion}

This paper has documented the construction of a virtual learning support service that overcomes geographical parameters and provides a practical service that can be accessed both on and off-campus. Furthermore, our initiative has shown how using an action research approach can be used to identify and address problems within the specific context of higher education.

Finally, while many challenges still exist in terms of how to address the pastoral dimensions of distance learning, the use of synchronous virtual classrooms has been shown here to go some way towards providing the relational dynamics frequently present among staff and students in on-campus classrooms and as such can be seen to enhance learner motivation in the achievement of learning outcomes.

\section{References}

Abbate, J. (2000) Inventing the internet. Cambridge: MIT Press.

Barnes, J.M. (1995). 'Embodiment, hermeneutic, alterity, and background relations on the Internet', paper presented at the Annual Meeting of the American Educational Research Association. San Francisco, 18-22 April.

Bates, T. (1997) 'The impact of technological change on open and distance learning', Distance Education, 18(1), pp. 93-109.

Becker, S.R and Watts, M.W. (2006) Teaching economics: more alternatives to chalk and talk. Cheltenham: Edward Elgar Publishing.

Bitzer, D., Lyman, E. and Easley, J. (1965) The uses of PLATO: a computer controlled teaching system. Urbana III., Coordinated Science Laboratory, University of Illinois, Report R-268. 
Brooks, L. (2003) 'How the attitudes of instructors, students, course administrators and course designers affects the quality of an online learning environment', Online Journal of Distance Learning Administration, 6(4). Available at:

http://www.westga.edu/ distance/ojdla/winter64/brooks64.htm (Accessed: 10 April 2009).

Campbell, E.M., Sittig, D.F., Guappone, K.P., Dykstra, R.H. and Ash, J.S. (2007) 'Overdependence on technology: an unintended adverse consequence of computerized provider order entry', American Medical Informatics Association: Annual Symposium Proceedings. Chicago, Illinois, USA10-14 November. Curran Associates Inc., pp. 94-98.

Carl, W. and Kemmis, S. (1986) Becoming critical: education, knowledge and action research. Basingstoke: Falmer Press.

Collis, B. and Moonen, J. (2001) Flexible learning in a digital world. London: Kogan Page.

De Graaff, E., \& Kolmos, A. (2007). History of problem-based and project-based learning. In E. de Graaff \& A. Kolmos (Eds.), Management of change: Implementation of problem based and project-based learning in engineering (pp. 1-8). Rotterdam: Sense Publishers.

Doyle, A. (2010) Disability service 10th anniversary symposium: a review of academic support services. Planning for the future. Dublin: Trinity College Dublin.

Dror, I.E. (2008) 'Technology enhanced learning: the good, the bad, and the ugly', Pragmatics and Cognition, 16(2), pp. 215-223.

Forster, E.M. (1909) The machine stops. Oxford and Cambridge Review. Available at: http://manybooks.net/titles/forstereother07machine stops.html (Accessed: 18 March 2012).

Fry, H. (2009) A handbook for teaching and learning in higher education: enhancing academic practice. 3rd edn. New York: Routledge. 
Fusco, M. and Ketcham, S.E. (2002) Distance learning for higher education: an annotated bibliography. Greenwood Village, CO: Libraries Unlimited Co.

Gagne, R. (1985) The conditions of learning. 4th edn. New York: Holt, Rinehart and Winston.

Gates, K. (2008) Elluminate vs. Dimdim vs. WizIQ vs. Adobe Acrobat Connect. Available at: http://moodle.org/mod/forum/discuss.php?d=93340 (Accessed: 8 May 2009).

Gerrard, C. (2002) 'Promoting best practice for e-tutoring through staff development', Proceedings of Networked Learning 2002: Third International Conference. Lancaster University and University of Sheffield $26^{-2} 28$ March.

Gerrard, C. (2005) 'Realising the full potential of e-learning: the search for a staff development model to support the repurposing of existing learning materials for effective online learning at the University of Paisley', Proceedings of the University of Paisley Research Conference. University of Paisley 1 December.

Greenwood, P.E. and Nikulin, M.S. (1996) A guide to chi-squared testing. New York: Wiley.

Hardy, J., Haywood, D., Haywood, J., Bates, S., Paterson, J., Rhind, S. and Macleod, H. (2009) ICT \& the student first year experience: a report from the LEaD Project. Available at:

http://www.jisc.ac.uk/media/documents/programmes/elearningpedagogy/leadfinalre port.pdf (Accessed: 11 June 2009)

Harper, B., Hedberg, J., Bennett, S. and Lockyer, L. (2000) Review of research. The online experience: the state of Australian on-line education and practices. South Australia: Australian National Training Authority.

Holmberg, B. (2005) The evolution, principles and practices of distance education. Oldenburg, Germany: Bibliotheks-und Informationssystem der Universitat Oldenburg. 
Hurley, T. (2009a) Assertiveness and influencing skills in the business environment .Lecture notes. Dublin: National College of Ireland.

Hurley, T. (2009b) Lecture two. Dublin: National College of Ireland.

Illeris, K. (2001) The three dimensions of learning. Denmark: Roskilde University Press.

Illeris, K. (2003) 'Towards a contemporary and comprehensive theory of learning', International Journal of Lifelong Education, 22(4), pp. 411-421.

Illeris, K. (2006) 'Lifelong learning and the low-skilled', International Journal of Lifelong Education, 25(1), pp. 15-28.

Kaufman, D.B., Felder, R.M. and Fuller, H. (2000) 'Accounting for individual effort in cooperative learning teams', Journal of Engineering Education, 89(2), pp. 133-140.

Lambert, J. (2009) Chi-square test. Dublin: National College of Ireland.

Lee, M.J.W. and Chan, A. (2007) 'Reducing the effects of isolation and promoting inclusivity for distance learners through podcasting', Turkish Online Journal of Distance Education, 8(1), pp. 85- 104.

Lewin, K. (1946) 'Action research and minority problems', in Lewin, G.W. (ed) (1948) Resolving social conflict. London: Harper and Row, pp. 201-216.

Macintyre, A. (2009) 'The very idea of a university: Aristotle, Newman and US', British Journal of Educational Studies, 57(4), pp. 347-362.

McMann, G.W. (1994) 'The changing role of moderation in computer mediated conferencing', Proceedings of the Distance Learning Research Conference. San Antonio, TX, 27-29 April, pp.159-166.

McPherson, M. and Nunes, M.B. (2004) The role of tutors as an integral part of online learning support. Available at: 
http://www.eurodl.org/materials/contrib/2004/Maggie MsP.html (Accessed: 12 January 2009).

Myers, G.J., Badgett, T., Thomas, T.M. and Sandler, C. (2004) The art of software testing. New Jersey: Wiley and Sons.

Muter, P., Treurniet, W.C. and Phillips, D. (1980) 'Computer-aided learning and videotex', Proceedings of the Third Canadian Symposium on Instructional Technology. Vancouver, Canada 27 February. Ottawa: National Research Council, pp. 319-325.

Newman, D.L., Falco, J., Silverman, S. and Barbanell, P. (2008) Videoconferencing technology in K-12 instruction: best practices and trends. London: Information Science Reference.

Newman, H. (1909) Historical Sketches Vol. III. (Revised 2002). London: Longmans, Green and Co.

Palloff, R.M. and Pratt, K. (2007) Building online learning communities: effective strategies for the virtual classroom. 2nd edn of building learning communities in cyberspace. New Jersey: Wiley and Sons.

Picciano, A.G. (2006) 'Online learning: implications for higher education pedagogy and policy', Journal of Thought, 41(1), pp. 75-94.

Power, D.J. (1990) 'The use of audio in distance education', in Timmers, S. (ed.) Training needs in the use of media for distance education. Singapore: Asian Mass Communication Research and Information Centre, pp.43-60.

Reddings, B. (1996) The university in ruins. Cambridge, MA: Harvard University Press.

Roberts, J.M. (1990) 'The idea of a university revisited', in Kerr, I. and Hill, A.G. (eds.) Newman after a hundred years. Oxford: Clarendon Press. (pp 193-223)

Rowntree, D. (1992) Exploring open and distance learning. London: Kogan Page. 
Roxanne Hiltz, S. (2006) 'The 'Virtual Classroom': using computer-mediated communication for university teaching', Journal of Communication, 36(2), pp. 95104.

Ryan, M.P. and Glenn, P.A. (2004) 'What do first-year students need most: learning strategies instruction or academic socialization?, Journal of College Reading and Learning, 34(2), pp. 4-28.

Shearer, L. (2003) Interaction in distance education. Special Report 2(1). Madison WI: Distance Educator.com and Atwood.

Smyth, R. (2005) 'Broadband videoconferencing as a tool for learner-centred distance learning in higher education', British Journal of Educational Technology, 36(5), pp. 805-820.

Stenhouse, L. (1975) An introduction to curriculum research and development. London, Heinemann.

The University of London (2009) Key facts. Available at: http://www.londonexternal.ac.uk/about us/facts.shtml Accessed: 2 January 2010).

Wiezel, A. (1998) 'Measuring the success of virtual tutoring', Proceedings of Frontiers in Education '98, ASU November 4-7 November, pp. 987-991.

Wood, H. (1995) Designing study materials for distance students. Occasional Papers in Distance Learning, 17. [Microfiche]. (ERIC Document Reproduction Service No. ED $385222)$.

Zywno, M.S. (2002) 'Instructional technology, learning styles and academic achievement', Proceedings of the 2002 American Society for Engineering Education Annual Conference and Exposition. Montreal, Canada 23-26 June. Available at: http://dissertation.readinesstechnology.com/papers/2002-Best-Overall-Paper-andPIC-V-Best-Paper.pdf (Accessed: 12 October 2009). 
Dr. Michael Goldrick has an Honours degree in Psychology and a PhD in Education. He has worked in Higher Education for seven years and currently manages the Learning Support Unit in National College of Ireland. Michael's research interests include learning development, blended learning, bullying and collaborative learning.

Correspondence to: michael.goldrick@ncirl.ie

Dr. James O'Higgins Norman is a lecturer and researcher in education at Dublin City University, I reland. He is the author of a number papers and books on bullying and pastoral care in education. His research interests include student support, bullying in schools and equality in education.

Correspondence to: james.ohigginsnorman@dcu.ie 